\title{
Why cardiovascular screening in young athletes can save lives: a critical review
}

\author{
Jonathan A Drezner, ${ }^{1}$ Kimberly G Harmon, ${ }^{1}$ Irfan M Asif, ${ }^{2}$ Joseph C Marek ${ }^{3}$
}

${ }^{1}$ Center for Sports Cardiology, University of Washington, Seattle, Washington, USA ${ }^{2}$ Department of Family Medicine, University of South Carolina, Greenville, South Carolina, USA

${ }^{3}$ Advocate Heart Institute, Chicago, Illinois, USA

\section{Correspondence to} Dr Jonathan A Drezner, Department of Family Medicine, Center for Sports Cardiology, University of Washington, Box 354060 Seattle, WA 98195, USA; jdrezner@uw.edu

Accepted 21 June 2016 Published Online First 14 July 2016
CrossMark

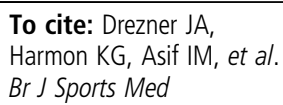

\section{ABSTRACT}

Cardiovascular (CV) screening in young athletes remains challenging and a topic of considerable debate. Recent criticisms of ECG screening have perpetuated arguments that ECG screening is neither indicated nor effective by applying outdated incidence data and flawed methodology. In response, this article provides a critical review of the arguments in favour of ECG screening in athletes and the early detection of CV disorders at elevated risk of sudden cardiac death (SCD). Importantly, no study to date has demonstrated that screening by history and physical examination alone is effective in detecting athletes at risk or in preventing SCD. ECG screening using current athlete-specific interpretation standards provides a low false-positive rate and improves detection of potentially lethal CV conditions. Further, risk reduction in athletes identified with $\mathrm{CV}$ disorders can be effectively achieved through modern strategies for risk stratification and disease-specific management. By every definition of the purpose of CV screening, ECG-inclusive programmes will better meet the stated objective of early detection when proper ECG interpretation and adequate cardiology resources are available. Less debate on screening protocols and more emphasis on advancing physician skills and infrastructure in sports cardiology is needed to more effectively screen targeted athlete populations.

\section{INTRODUCTION}

In a recent $B M J$ report, Van Brabandt et $a l^{1}$ assessed cardiovascular (CV) screening in athletes to prevent sudden cardiac death (SCD) from the perspective of a health economist. The authors make several points with which we agree: (1) the diagnostic yield of CV screening by history and physical examination alone is extremely low and has little supporting evidence; (2) national, universal screening should not be mandated, especially without appropriate physician infrastructure; (3) CV screening will detect disorders associated with SCD but with an unclear absolute risk of CV events and (4) the potential benefits and harms of different $\mathrm{CV}$ screening programmes are not fully understood. However, we firmly disagree with their conclusion, 'As long as those at high risk of sudden death cannot reliably be identified and appropriately managed, young athletes should not be submitted to pre-participation screening'. We argue that athletes with conditions at risk of SCD can be successfully identified and appropriately managed. Thus, we share our perspective on why early detection of $\mathrm{CV}$ disorders in athletes is justified and can save lives.

\section{REFRAMING THE DEBATE}

Once again ECG screening is presented as a binary 'all or none' response-either mandated as a national programme and provided to athletes at all levels or not recommended at all. These polarised options provide little assistance to physicians responsible for preparticipation screening and lack considerations that drive sound medical practice, specifically an assessment of individualised risk and physician skills and resources.

Few preventive services are performed in medicine without accounting for individual patient risk. Robust data from independent data sets prove that some athlete groups have a substantially higher risk than others. ${ }^{2}{ }^{3}$ In the USA, black male college athletes have an annual SCD risk of 1 in 16000 , male basketball athletes 1 in 9000 and male black basketball athletes 1 in $4400 .^{2}$ These rates are not 'extremely rare' but alarmingly high.

\section{PURPOSE AND ASSUMPTIONS}

The premise of CV screening in athletes is that early detection of cardiac disorders associated with SCD can reduce morbidity and mortality through individualised and evidence-driven disease-specific management. Without believing in the benefit of early detection, then screening by any strategy is called into question. If one believes in early detection, screening by history and physical examination alone is inadequate. The addition of ECG, while still imperfect, will increase detection of disorders at elevated risk of SCD and can be achieved with a low false-positive rate and with high quality when proper infrastructure and skilled cardiology resources are available. In two independent studies of CV screening in college athletes (total $\mathrm{N}=1664$ ), the ECG abnormal rate in both studies using the Seattle criteria was only $2.8 \%$ (with false-positive rates $<2.5 \%$ ), and all potentially lethal CV disorders-hypertrophic cardiomyopathy (3), long QT syndrome (1) and ventricular pre-excitation (4)were found only because of ECG abnormalities and would have been missed by an evaluation using history and physical examination alone. ${ }^{45}$

\section{A CALL FOR COMPARABLE SCRUTINY}

Van Brabandt et al question the incidence rates in a 25-year Italian study while overlooking serious methodological limitations in the studies cited in opposition. ${ }^{6}$ Incidence data depend greatly on the method used to identify cases, and we provide three clarifications. First, the high incidence at the beginning of the Italian study is consistent with that of other studies using a mandatory reporting system, specifically data from the US military, ${ }^{7}$ and is unlikely to be 'simple random variation'. If the 
Figure 1 Annual risk of SCD in athletes from Veneto, Italy ${ }^{6}$ and Minnesota, ${ }^{13}$ and more recent incidence data in NCAA college

The differential risk of SCD in targeted athlete populations should be considered when choosing an appropriate CV screening strategy. Graph adapted from Corrado et al. ${ }^{6}$ $\mathrm{CV}$, cardiovascular; $\mathrm{SCD}$, sudden cardiac death. athletes $^{2}$ and US military personnel. ${ }^{7}$

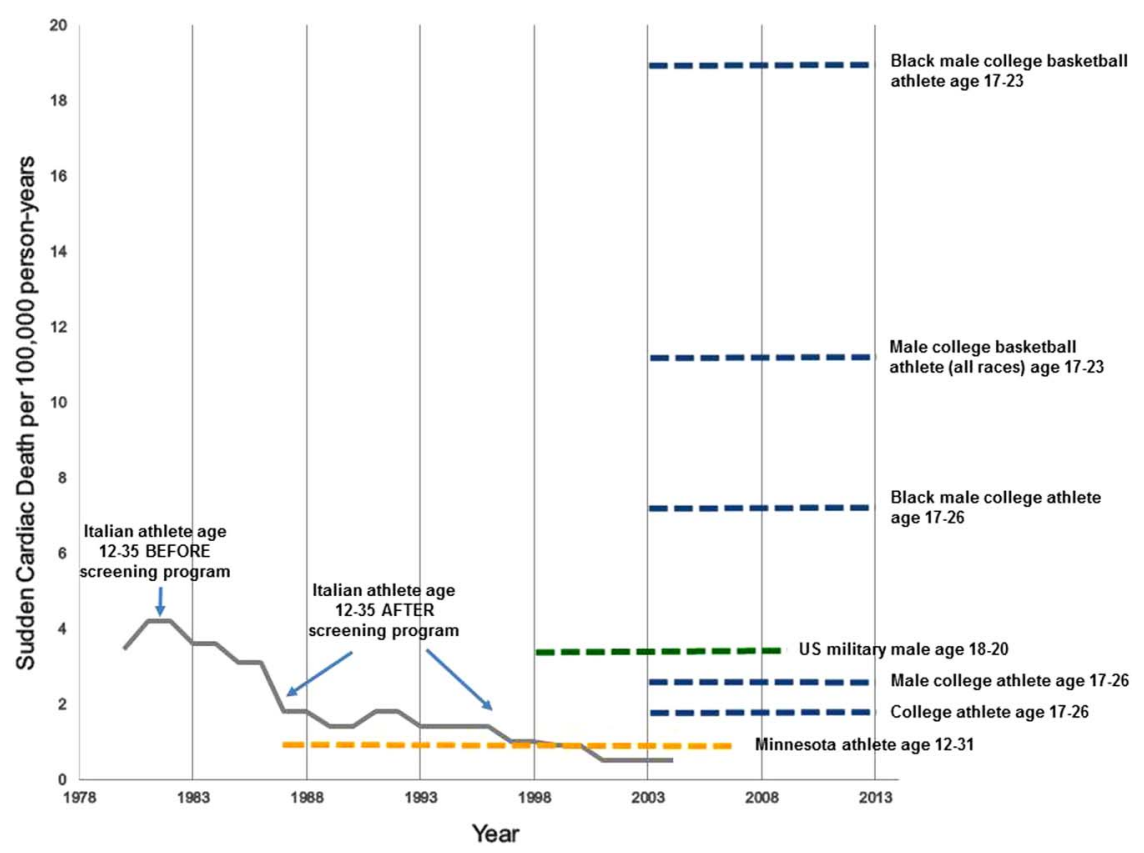

high initial incidence was an anomaly, why did it last nearly 8 years before decreasing? Second, because the data from Israel relied on a retrospective review of newspaper clippings for case identification, the study is fatally flawed. ${ }^{8} 9$ This approach must have misestimated SCD cases over the 24-year period making any comparison of screening strategies unreliable as other studies demonstrate that case capture methods by media reports identify only $18-56 \%$ of SCD cases in athletes. ${ }^{10-12}$ Third, Van Brabandt references incidence estimates from Minnesota to suggest that the incidence rate of SCD in the USA (without ECG screening) is no different from the incidence rate of SCD in Italy. ${ }^{13}$ However, the low incidence reported in Minnesota does not represent current estimates in the USA. This number is again an underestimate and derived largely from catastrophic insurance claims in high school athletes-a mechanism for case identification revealed to be inadequate in a detailed analysis. ${ }^{14}$ We argue that Van Brabandt's failure to critically examine the methodology in each study explains their conclusion-one that is therefore misleading. Applying recent incidence data leads to a different conclusion when choosing an appropriate CV screening strategy, especially in athletes deemed high risk (figure 1).

\section{DISEASE-ORIENTED OUTCOMES EVIDENCE}

Is a randomised trial the only evidence that will support early detection through ECG screening? Van Brabandt et al make no reference to the mounting disease-specific data that early detection of pathological cardiac disorders followed by individualised risk stratification and management lowers mortality for some cardiac conditions. For example, large cohort studies using current therapeutic measures have demonstrated improved survival and low mortality rates in children and young adults with hypertrophic cardiomyopathy. ${ }^{16}{ }^{17}$ For children diagnosed with long QT syndrome, individualised management and in-depth counselling were associated with low cardiac event rates and no deaths in two independent cohorts of young athletes. ${ }^{18} 19$ For asymptomatic athletes identified with ventricular pre-excitation (Wolff-Parkinson-White pattern), expert consensus guidelines define risk stratification and management strategies to reduce risk. $^{20}{ }^{21}$ Lastly, updated eligibility recommendations from the
American College of Cardiology also affirm that early detection of conditions at risk has the potential for individual benefit. ${ }^{22}$

\section{MOVING FORWARD}

The primary goal of CV screening in competitive athletes is to detect cardiac disorders early in their natural history to mitigate the risk of SCD through risk stratification, individualised management and evidence-driven activity recommendations. Successful ECG screening programmes require accurate ECG interpretation using modern athlete-specific standards, as well as skilled cardiology resources for the secondary evaluation of ECG abnormalities. ${ }^{23}$ When CV screening programmes that include ECG are performed with quality, approximately one in six abnormal ECGs will represent a relevant cardiac disorder at elevated risk of SCD. ${ }^{4} \mathrm{CV}$ screening remains ethically compelling in high-risk athletes until a proper study demonstrates otherwise. We agree with Van Brabandt that national mandates are not appropriate. That is not the question. We argue (and present data) that to provide safe sports participation, the focus of preventing SCD in athletes should be on the development of a trained physician infrastructure to conduct more effective screening for targeted athlete populations.

\section{What are the findings?}

- Cardiovascular screening in athletes is not effectively accomplished using history and physical examination alone.

- ECG screening should not be a choice between mandated, national programmes or not being conducted at all. The differential risk of targeted athlete populations and an assessment of physician skills and resources should be used to guide screening practices.

- Current incidence studies provide robust evidence from independent data sets that some athlete groups have a substantially higher risk of SCD than that of others.

- Early detection of cardiac disorders associated with SCD can reduce morbidity and mortality through individualised and evidence-driven disease-specific management. 
How might it impact on clinical practice in the future?

When cardiovascular screening in young athletes is recommended, ECG-inclusive strategies represent best practice when proper ECG interpretation and adequate cardiology resources are available. A greater emphasis on physician training and infrastructure is needed to conduct more effective screening in high-risk athlete populations.

Competing interests None declared.

Provenance and peer review Not commissioned; internally peer reviewed.

\section{REFERENCES}

1 Van Brabandt $H$, Desomer A, Gerkens $S$, et al. Harms and benefits of screening young people to prevent sudden cardiac death. BMJ 2016;353:11156.

2 Harmon KG, Asif IM, Maleszewski JJ, et al. Incidence, cause, and comparative frequency of sudden cardiac death in national collegiate athletic association athletes: a decade in review. Circulation 2015;132:10-19.

3 Maron BJ, Haas TS, Murphy CJ, et al. Incidence and causes of sudden death in U.S. college athletes. J Am Coll Cardiol 2014;63:1636-43.

4 Drezner JA, Prutkin JM, Harmon KG, et al. Cardiovascular screening in college athletes. J Am Coll Cardiol 2015;65:2353-5.

5 Fuller C, Scott C, Hug-English C, et al. Five-year experience with screening electrocardiograms in National Collegiate Athletic Association Division I Athletes. Clin J Sport Med 2016 Feb 15. [Epub ahead of print]

6 Corrado D, Basso C, Pavei A, et al. Trends in sudden cardiovascular death in young competitive athletes after implementation of a preparticipation screening program. JAMA 2006;296:1593-601.

7 Eckart RE, Shry EA, Burke AP, et al. Sudden death in young adults an autopsy-based series of a population undergoing active surveillance. J Am Coll Cardiol 2011;58:1254-61.

8 Steinvil A, Chundadze T, Zeltser D, et al. Mandatory electrocardiographic screening of athletes to reduce their risk for sudden death proven fact or wishful thinking? J Am Coll Cardiol 2011;57:1291-6.

9 Drezner JA, Harmon KG, Borjesson M. Incidence of sudden cardiac death in athletes: where did the science go? Br J Sports Med 2011;45:947-8.

10 Harmon KG, Asif IM, Klossner D, et al. Incidence of sudden cardiac death in national collegiate athletic association athletes. Circulation 2011;123:1594-600.
11 Holst AG, Winkel BG, Theilade J, et al. Incidence and etiology of sports-related sudden cardiac death in Denmark-implications for preparticipation screening. Heart Rhythm 2010;7:1365-71.

12 Risgaard B, Tfelt-Hansen J, Winkel BG. Sports-related sudden cardiac death: how to prove an effect of pre-participation screening? Heart Rhythm 2016;13:1560-2.

13 Maron BJ, Haas TS, Doerer JJ, et al. Comparison of U.S. and Italian experiences with sudden cardiac deaths in young competitive athletes and implications for preparticipation screening strategies. Am J Cardiol 2009;104:276-80.

14 Roberts WO, Stovitz SD. Incidence of sudden cardiac death in Minnesota high school athletes 1993-2012 screened with a standardized preparticipation evaluation. J Am Coll Cardiol 2013;62:1298-301.

15 Drezner JA, Harmon KG, Marek JC. Incidence of sudden cardiac arrest in Minnesota high school student athletes: the limitations of catastrophic insurance claims. J Am Coll Cardiol 2014;63:1455-6.

16 Maron BJ, Rowin EJ, Casey SA, et al. Hypertrophic cardiomyopathy in children, adolescents, and young adults associated with low cardiovascular mortality with contemporary management strategies. Circulation 2016;133:62-73.

17 Maron BJ, Maron MS. Contemporary strategies for risk stratification and prevention of sudden death with the implantable defibrillator in hypertrophic cardiomyopathy. Heart Rhythm 2016;13:1155-65.

18 Johnson JN, Ackerman MJ. Return to play? Athletes with congenital long QT syndrome. Br J Sports Med 2013;47:28-33.

19 Aziz PF, Sweeten T, Vogel RL, et al. Sports participation in genotype positive children with long QT syndrome. JACC Clin Electrophysiol 2015;1:62-70.

20 Cohen MI, Triedman JK, Cannon BC, et al. PACES/HRS expert consensus statement on the management of the asymptomatic young patient with a

Wolff-Parkinson-White (WPW, ventricular preexcitation) electrocardiographic pattern: developed in partnership between the Pediatric and Congenital Electrophysiology Society (PACES) and the Heart Rhythm Society (HRS). Endorsed by the governing bodies of PACES, HRS, the American College of Cardiology Foundation (ACCF), the American Heart Association (AHA), the American Academy of Pediatrics (AAP), and the Canadian Heart Rhythm Society (CHRS). Heart Rhythm 2012;9:1006-24.

21 Al-Khatib SM, Arshad A, Balk EM, et al. Risk stratification for arrhythmic events in patients with asymptomatic pre-excitation: a systematic review for the $2015 \mathrm{ACC}$ / AHA/HRS guideline for the management of adult patients with supraventricular tachycardia: a report of the American College of Cardiology/American Heart Association Task Force on Clinical Practice Guidelines and the Heart Rhythm Society. Circulation 2016;133:e575-86.

22 Maron BJ, Zipes DP, Kovacs RJ. Eligibility and disqualification recommendations for competitive athletes with cardiovascular abnormalities: preamble, principles, and general considerations: a scientific statement from the American Heart Association and American College of Cardiology. J Am Coll Cardiol 2015;66: 2343-9.

23 Drezner JA, Ackerman MJ, Anderson J, et al. Electrocardiographic interpretation in athletes: the 'Seattle criteria'. Br J Sports Med 2013;47:122-4. 